\title{
The relation between central corneal thickness, axial length and myopia among a sample of patients in Erbil
}

\begin{tabular}{c}
\hline Kurdo Mohammedamin Omer * Ahmed Kareem Joma ** \\
\hline Abstract
\end{tabular}

Background and objective: Myopiais a common refractive error in the estimation of corneal barrier and well-beingof endothelial function, the central corneal thickness is important to manage corneal diseases. This study aimed to explore the relationship between central corneal thickness, axial length and myopia among a sample of patients in Erbil.

Methods: This cross-sectional study was conducted from June 2015 to February 2016. Forty six emmetropes as a control group and 46 myopes were studied. Axial length was measured with A-scan ultrasound biometry and central corneal thickness with corneal topography. Central corneal thickness was correlated with myopia and axial length using the Pearson's correlation coefficient.

Results: This study included 92 patients. The mean age of myopes was 31.87 years and 33 years for emmetropes. Myopia ranged from -0.5 to -11 diopters. The mean central corneal thickness was 541.80 micrometers for myopes and 548.93 micrometersfor emmetropes. The mean axial length was 25.77 millimetersfor myopes and 24.37 millimetersfor emmetropes.The Pearson's correlation coefficient $(r)$ of the central corneal thickness and myopia was $-0.0245(P=0.872)$, while that of the central corneal thickness and axial length in myopes was $0.035(P=0.566)$ and of the central corneal thickness and axial length in emmetropes was $0.26(P=0.091)$.

Conclusion: There was no correlation between central corneal thickness, axial length and myopia.

Keywords: Myopia; Central corneal thickness; Axial length.

\section{Introduction}

Myopia is reported to be a common refractive errorin Asian countries. ${ }^{1}$ It results from a complex genetical and environmental factors. ${ }^{2}$ In this situation, parallelrays of light which are entering theeye cannot be focusedon the retina, and the picturefalls in front of the retina. ${ }^{3}$ Various subsets of myopia have been recognized. Juvenile-onset myopia, described as myopia which starts between 7 and 16 years of age, is primarily due to growth in the axial length of the eyeball. ${ }^{4}$ Adult-onset myopiastarts at about 20 years of age, and it is mainly caused by extensive near handiwork. ${ }^{4}$ However, the etiology of the development of myopia is not well known, Two-thirds of the optical refraction is produced by the cornea. Therefore, its role in myopia has been studied greatly over many years. ${ }^{5}$ The myopic changes of the eyes involve increased depth of anterior chamber, elongation of axial length, thinning of the retina which is associated with lattice changes and a higher rate of retinal detachment, decreased choroidal blood flow, and decrease in thickness and elasticity of sclera. ${ }^{1}$ It is known that the myopic eye is longer than the emmetropic eye. If this resulted from the general growth of the eyeball, we might expect that the cornea is growing thicker than normal. If instead,

* Erbil Directorate of Health, Erbil, Iraq.

** Department of Surgery, College of Medicine, Hawler Medical University, Erbil, Iraq. 
the mechanism behind myopic eye enlargement is similar to that of balloon inflation, the expectation will be thinner cornea than normal according to the stretching theory. ${ }^{5}$ It has been reported that central corneal thickness (CCT) is a well-known indicator of corneal health. In the estimation of the corneal barrier and endothelial functional well-being, CCT is important to assess and manage corneal diseases. ${ }^{6}$ Furthermore, CCT is an indicator of corneal rigidity and it affects the accuracy of measuring the intraocular pressure. In addition, CCT values are highly important during the pre-operative assessment of patients undergoing corneal refractive surgeries. These values are also helpful in the decision making as for whether or not to perform surgery, the type of suggested procedure, and the rate of complications after surgery. ${ }^{1}$ Studies that were undertaken to explore the effect of refractive errors on CCT have revealed conflicting results. Some studies have reported that myopic patients have a thicker $\mathrm{CCT}^{.7}$ Others have found that CCT is thinner in myopic eyes, ${ }^{8-11}$ while some studies have reported no association between central corneal thickness and degree of myopia. ${ }^{12-22}$ The results of this study will help the refractive surgeons how to evaluate and choose the type of the refractive surgeries like the laser in situ keratomileusis and photorefractive keratectomy for myopic patients and to assess the risk of postoperative complications. The purpose of this study was to determine the correlation between central corneal thickness, axial length and myopia.

\section{Methods}

\section{Design of the study:}

A hospital based cross-sectional study (with a control group) was conducted in ophthalmology department of Erbil and Rizgary teaching hospitals in Erbil city from June 2015 to February 2016. 92 consecutive patients were enrolled in the study. Patients were divided into an emmetropic group and a myopic group. The inclusion criteria included adults 18 years of age or older, patients with normal visual acuity for the emmetropic group and patients with spherical myopia from 0.50 and greater for the myopic group. The exclusion criteria included subjects with active ocular or corneal disease and corneal dystrophies, patients who had been treated previously for glaucoma and ocular hypertension, diabetics or other systemic disease possibly affecting the corneal thickness, eyes with keratoconus as demonstrated by corneal topography, previous corneal or ocular surgery and contact lens use for 2 weeks in case of soft lenses and 3 weeks for hard lenses before examination were excluded. Complete ophthalmic evaluation and slit lamp (Topcon, Tokyo optical CO., LTD. Japan) examination was done for all patients. Manifest refraction was done for all patients by Auto kerato-refractometer K.R8800 (Topcon Corporation, Japan). The axial length of both eyes was measured by using ultrasonic $A$ scan AL -6000 (Honda electronics CO., LTD, Japan) after installation of a drop of tetracaine $0.5 \%$ into each eye. Corneal topography was done by using Galilei G4 [dual scheimpflug analyzer] (Ziemer ophthalmic systems AG allmendstrasse $11 \mathrm{CH}-2562$ port, Switzerland) for measuring central corneal thickness. Galilei measurements were obtained as per the manufacturer's instructions. The patient was comfortably sat with chin fully placed on the chin rest and forehead against the strap. The patient looked at the target (red spot) and allowed to blink. The device was brought in focus by aligning the measurement head of the Galilei. Alignment was considered correct when the red cross passed through the white spots and the single red line touch the corneal epithelium. The iris was seen in sharp focus on the screen. The patient was asked to blink once, open the eye wide and the reading was taken. 


\section{Ethical issue:}

The study was approved by the Research Ethics Committee of the College of Medicine of Hawler Medical University and verbal informed consent was taken from each participant before being enrolled in the study.

\section{Statistical analysis:}

The data were entered and analyzed using the statistical package for the social sciences computer program (version 21). The calculated descriptive statistics were tabulated by mean and standard deviation (SD). The correlation between CCT, axial length and myopia was studied using Pearson's correlation co-efficient (r-value more than 0.7 was considered as strong correlation). Student t-test was used to compare means from two independent groups and statistical significance is assumed at the $P<0.05$ level.

\section{Results}

A total of 92 patients (184 eyes) were recruited for the study; 46 patients were myopes and 46 patients were controls. There were 48 female patients and 44 male patients. Patients in the age group 19 to 49 years in myopic patients and $19-50$ in emmetropic group were included in the study. The mean age was 31.87 years (SD 7.99 , median 31 years) in myopic group and 33 years (SD 8.08, median 33yrs) in emmetropic group (Table 1). The distribution of patients according to the degree of myopia is shown in Figure 1.

Table 1: Characteristics of study patients.

\begin{tabular}{lcc}
\hline & Myopic group & Control group \\
\hline No. of patients & 46 & 46 \\
Age & & \\
Mean(SD) & $31.87(7.99)$ & $33(8.08)$ \\
Median & 31.00 & 33 \\
Range(years) & $19-49$ & $19-50$ \\
Gender & & \\
Male & 22 & 22 \\
Female & 24 & 24 \\
\hline
\end{tabular}

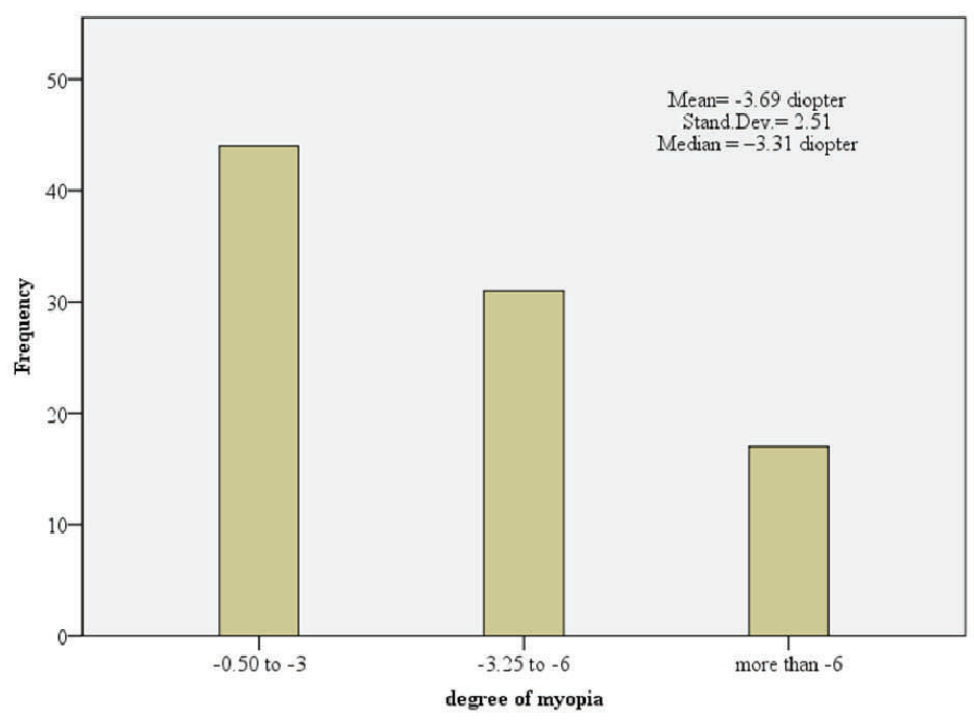

Figure 1: Histogram showing distribution of patients according to the degree of myopia. 
CCT was split into groups (Table 2). The difference between the two CCT 48 of the 92 myopic eyes had a CCT range of 500 - 549 micrometers and 36 of 92 emmetropic eyes had a CCT range of $500-549$ micrometers. Table 3 summarizes the features of CCT and axial length in patients. In the myopic group, the mean CCT was $541.8 \mathrm{~mm}$ (SD 40.09, range $432-619 \mathrm{~mm}$, median $540.25 \mathrm{~mm}$ ) and the mean axial length was 25.77 millimeters $(\mathrm{mm})$ (SD 1.55, range 23.26 $28.78 \mathrm{~mm}$, median $25.42 \mathrm{~mm}$ ). In the emmetropic group, the mean CCT was $548.93 \mathrm{~mm}$ (SD 38.87, range 467-626 mm, median $547 \mathrm{~mm}$ ) and the mean axial length was $24.37 \mathrm{~mm}$ (SD 0.95, range 22.06 - $25.83 \mathrm{~mm}$, median $24.60 \mathrm{~mm}$ ). means was statistically significant $(p<0.05$, students t-test) and the difference between the two axial means was statistically significant $(P<0.05$, Students t-test). The correlation between CCT, axial length and myopia was analyzed using the Pearson's Correlation Coefficient. There was no significant correlation between CCT and axial length in myopes, $r=0.035, P=0.566$ and there was no significant correlation between CCT and axial length in emmetropes, $r=0.26, P=0.091$. There was no significant correlation between CCT and degree of myopia, $r=-0.024, P=0.872$ (Table 4).

Table 2: Distribution of eyes by degree of central corneal thickness.

\begin{tabular}{lcc}
\hline CCT(micrometer) & No. of myopic eyes & No. of emmetropic eyes \\
\hline Less than $500 \mathrm{~mm}$ & 14 & 12 \\
$500-549 \mathrm{~mm}$ & 48 & 36 \\
$550-600 \mathrm{~mm}$ & 24 & 35 \\
More than $600 \mathrm{~mm}$ & 6 & 9 \\
Total & 92 & 92 \\
\hline
\end{tabular}

Table 3: Characteristics of CCT and axial length in patients.

\begin{tabular}{lcc}
\hline & Myopic group & Emmetropic group \\
\hline CCT(micrometer) & $541.80(40.09)$ & $548.93(38.87)$ \\
Mean(SD) & 540.25 & 547.0 \\
Median & $432-619$ & $467-626$ \\
Range & & \\
Axial length(millimeter) & $25.77(1.55)$ & $24.37(0.95)$ \\
Mean(SD) & 25.42 & 24.60 \\
Median & $23.26-28.78$ & $22.06-25.83$ \\
Range & &
\end{tabular}

Table 4: Correlation between CCT, axial length and myopia.

\begin{tabular}{lcc}
\hline Pearson's correlation analysis & Correlation co-efficient & $\boldsymbol{P}$ value \\
\hline CCT and myopia & -0.0245 & 0.872 \\
CCT and axial length in myopes & 0.035 & 0.566 \\
CCT and axial length in emmetropes & 0.26 & 0.091 \\
\hline
\end{tabular}




\section{Discussion}

Although numerous investigators have studied the effect of refractive error on CCT investigators, conflicting results have been found. Myopia increases with advancing age. In the United States, the prevalence of myopia varies in different age groups, it's about $3 \%$ among children 5 to 7 years old age, $8 \%$ among 8 to 10 years age group, $14 \%$ among 11 to 12 years age group, and among those aged 12 to 17 years it is about $25 \%$. In particular racial groups, a similar trend has been recognized, however the percentages may differ in each age group. ${ }^{4}$ During progression of myopia the eyeball is elongated. This progression makes the eyeball become longer also makes the sclera to become thinner ${ }^{23-25}$ and the posterior part of sclera is involved more significantly. ${ }^{26,27}$ In addition to the fact that the anterior chamber is deeper in higher myopia ${ }^{28}$ there are dimensional alterations in the anterior segment during progression of myopia, but they are not well documented. Goss and his colleagues ${ }^{29}$ have found flatter corneal surfaces in eyes with deeper vitreous cavities. If the whole corneal size is not increased, we suppose that the cornea becomes thinner in a similar manner to sclera during progression of myopia. However, in our study we didn't find any statistically significant relation between central corneal thickness and myopia (Pearson $r=-0.0245 P=0.872$ ). This finding agrees with the most of the earlier studies. ${ }^{12-22}$ According to such findings, we consider that if the stretching process is actually active, the thinning is likely to be restricted only to the sclera and the cornea is not involved. The current study has the limitation that we measured CCT in the morning and there are studies that investigated the diurnal changes of corneal thickness with various techniques. One of these studies is by Muller-Treiber et al. ${ }^{30}$ who studied the diurnal variations with the optical low coherence reflectometry (OLCR) pachymeter, and reported that the cornea is thickest in the morning and about 5 micrometer lower in the late afternoon. The inconclusive findings of earlier studies could be clarified by each of the following factors: low reproducibility of pachymeters, inexperienced examiners, racial and genetic variations in CCT, the effect of contact lenses, deficiency of high myopic subjects, the difference in exclusion criteria and small sample sizes. In our study, we used corneal topography which is the most precise instrument nowadays for measuring corneal thickness than older instruments which were used by previous studies. There looks to be no general agreement regarding the relation between CCT and axial length. The present study showed no association between CCT and axial length. This result agrees with a conclusion by Oliveira et al. ${ }^{20}$ who reported no association between CCT and axial length in American patients. In addition, Mitsugu Shimmyo et al. ${ }^{31}$ who studied ocular parameters of 1084 eyes. They didn't find a statistically significant correlation between CCT and axial length. They also analyzed the subgroups by gender, age and race, but failed to find a significant association. In contrary, Chang et al. $^{10}$ showed that eyes with greater axial lengths have significant thinner CCTs. They considered that the cornea became thinner as its surface area is increased, and decreased corneal thickness might be anticipated as the axial length of the eye increases. Their subpopulation is possibly very small to give a reliable relation between CCT and axial length in the whole population. Myopia may become a progressing problem in the future as its prevalence is increasing. Investigations in Japan, Iceland, Denmark and North American native populations have found that the prevalence of myopia is increasing. Therefore, in the future years there will be a higher rate of refractive surgeries for correction of myopia. There is a general agreement that with Lasik, the cornea should not be thinned further than a given value. Therefore, the measurement of corneal thickness 
is necessary before surgery.

\section{Conclusion}

In our study, we didn't find significant relations between central corneal thickness, axial length and the level of myopia. Our findings add to the fact that CCT and axial lengthare independent elements and are not related to other ocular parameters. Therefore, we consider that the central corneal thickness is not involved with the growth changes in ocular tunics of myopic patients. We recommend that in the future studies the central corneal thickness to be measured in the late afternoon to avoid the diurnal variation in corneal thickness.

\section{Competing interests}

The authors declare that they have no competing interests.

\section{References}

1. Al-Mezaine HS, Al-Obeidan S, Kangave D, Sadaawy A, Wehaib TA, Al-Amro SA. The relationship between central corneal thickness and degree of myopia among Saudi adults. J Int Ophthalmol 2009; 29(5):373-8.

2. Kanski JJ, Browling B, Nischal K, Pearson A. Clinical ophthalmology: A systematic approach. $7^{\text {th }}$ ed. Edinburgh: Elsevier Saunders; 2011. P.812.

3. Snell RS, Lemp MA. Clinical anatomy of the eye. $2^{\text {nd }}$ ed. USA: Blackwell Science; 1998. P.204.

4. Zorab RA, Straus H, Arturo C, Tanaka S, Ray J, Veen B, et al. Basic and Clinical Science Course. Clinical optics section 3. San Francisco, USA: American academy of ophthalmology; 2011. p.118.

5. Elias A,Giridhar A, Mahhesh G, Bhat S, Kumar R. Central corneal thickness and relating factors. KJ Ophthalmol 2009; 56(2):149-53.

6. Mishima S. Corneal thickness. Surv Ophthalmol 1968; 13:57-96.

7. Kunert KS, Bhartiya P, Tandon R, Dada T, Christian $H$, Vajpayee RB. Central corneal thickness in Indian patients undergoing LASIK for myopia. J Refract Surg 2003; 19:378-9.

8. Von-Bahr G. Corneal thickness: its measurement and changes. Am J Ophthalmol 1956; 42:25166.

9.Chang SW, Tsai IL, Hu FR, Lin LK, Shih FY. The cornea in young myopic adults. $\mathrm{Br} \mathrm{J}$ Ophthalmol 2001; 85:916.

10. Chang SW, Tsai IL, Hu FR, Lin LL, Shih YF. The cornea in young myopic adults. $\mathrm{Br} \mathrm{J}$ Ophthalmol 2001; 85:961-70.
11. Srivannaboon S. Relationship between corneal thickness and level of myopia. J Med Assoc Thai 2002; 85:162-6.

12. European Glaucoma Prevention Study Group, Pfeiffer N, Torri V, Miglior S, Zeyen T, Adamsons I, Cunha-Vaz J. Central corneal thickness in the European Glaucoma Prevention Study. Ophthalmology 2007; 114: 454-9.

13. Chen YC, Kasuga T, Lee HJ, Lee SH, Lin SY. Correlation between central corneal thickness and myopia in Taiwan. Kaohsiung J Med Sci 2014; 30: 20-4.

14. Garcia-Medina M, Garcia-Medina JJ, GarridoFernandez P, Galvan-Espinosa J, Martin-Molina J, Garcia-maturana C, et al. Central corneal thickness,intraocular pressure and degree of myopia in an adult myopic population aged 20 to 40 years in southeast Spain:determination and relationships. Clin Ophthalmol 2011; 5:249-58.

15.Tanaka HM, Mori ES, Maia N, Freitas D, Campos $\mathrm{M}$, Chamon W. Corneal thickness in high myopes. Invest Ophthalmol Vis Sci 1996; 37:2566.

16. Price FW, Koller DL, Price MO. Central corneal pachymetry in patients undergoing laser in situ keratomileusis. Ophthalmology 1999; 106:221620.

17. Cho P, Lam C. Factors affecting the central corneal thickness of Hong Kong Chinese. Curr Eye Res 1999; 18:368-74.

18. Liu Z, Pflugfelder SC. The effects of long-term contact lens wear on corneal thickness, curvature, and surface regularity. Ophthalmology 2000; 107:105-11.

19. Aghaian E, Choe JE, Lin S, Stamper RL. Central corneal thickness of Caucasians, Chinese, Hispanics, Filipinos, African Americans, and Japanese in a glaucoma clinic. Ophthalmology 2004; 111:2211-9.

20. Oliveira C, Tello C, Liebmann J, Ritch R. Central corneal thickness is not related to anterior scleral thickness or axial length. J Glaucoma 2006; 15:190-4.

21. Fam HB, How AC, Baskaran M, Lim KL, Chan $\mathrm{YH}$, Aung T. Central corneal thickness and its relationship to myopia in Chinese adults. $\mathrm{Br} \mathrm{J}$ Ophthalmol 2006; 90:1451-3.

22. Pfeiffer N, Torri V, Miglior S, Zeyen T, Adamsons I, Cunha-Vaz J. The European Glaucoma Prevention Study Group. Central corneal thickness in the European Glaucoma Prevention Study. Ophthalmology 2009; 114:454-9.

23. Lin LL, Shih YF, Tsai CB, Chen CJ, Lee LA, Hung PT,et al. Epidemiologic study of ocular refraction among schoolchildren in Taiwan in 1995. Optom Vis Sci 1999; 76:275-81.

24. Funata $M$, Tokoro $T$. Scleral change in experimentallymyopic monkeys. Graefes Arch Clin Exp Ophthalmol 1990; 228:174-9.

25. Phillips JR, McBrien NA. Form deprivation myopia: elastic properties of sclera. Ophthalmic Physiol Opt 1995; 15:357-62. 
26. Celorio JM, Pruett RC. Prevalence of lattice degeneration and its relation to axial length in severe myopia. Am J Ophthalmol 1991; 111:20-3.

27. Lam CS, Edward M, Millodot M, Goh WS. A 2-year longitudinal study of myopia progression and optical component changes among Hong Kong schoolchildren. Optom Vis Sci 1999; 76:37080.

28. Curtin BJ. Ocular findings and complications. In: The myopias: basic science and clinical management. Harper and Row: Philadelphia; 1985. P 277-385.

29. Goss DA, Van veen HG, Rainey BB, Feng B. Ocular component measured by keratometry, phakometry, and ultrasonography in emmetropic and myopic optometry student. Optom Vis Sci 1997; 74:489-95.

30. Muller-Treiber A, Joos RE, Bussacker H, Schmid $P$, Trachsel M. Vera"nderung der Corneadicke unter Silicon-Hydrogellinsen gemessen mit dem Breitbandreflektometer. Die Kontaktlinse 2001; 7-8:11-6.

31. Mitsugu Shimmyo, Pasul N. Orloff. Corneal Thickness and Axial Length. Am J Ophthalmol 2005; 139:553-4. 